\title{
Research Review on Evaluation Index for Age-friendly Community - a Case Study of Tianjin City
}

\author{
Jia Weiyang ${ }^{1,}$, , Wang Xiaorong ${ }^{2, b}$ \\ ${ }^{1,2}$ School of Architecture, Tianjin University, No.92 Weijin Road, Nankai District, Tianjin, P.R.China \\ ailaweiy@163.com, btjuwxr@163.com, corresponding author
}

\begin{abstract}
Keywords: The elderly, Age-friendly community, Evaluation index.
Abstract: China is facing social difficulties of severe aging trend that retirement community has become a promoting new type of aging life model beside "family support" and "institution care". Retirement community requires higher quality of environment design and facility layout, and demands improving evaluation index system. By field investigation on daily life of the elderly in 100 communities from large cities with high portion of aged population in different areas of China, the distribution of the elderly activities in time and space can be analyzed and summarized, as well as the subjective requirements for functionality and safety of the community public space and facilities. With statistical analysis of survey data, the correlations between "age- friendliness" and environment design or facilities and services are explored, factors behind the subjective evaluation are found, and a set of relatively objective satisfaction evaluation index system for retirement community is established, as a guide for community reconstruction or new retirement community plan.
\end{abstract}

\section{Introduction}

China is facing the social difficulties of serious aging problem before getting rich and prepared for it, according to the Sixth national census data in 2010 which showed that China's population over 60 had reached 177.6 million, accounting for $13.26 \%$ of the total population [1]; and it will reach $430 \sim$ 450 million in 2050 , or one third of the total population. Under the situation, community care had become a new pension model beside family care and institution care, since the State Council established the goal "family care based, community care backed, institution care supported" in the 12th five-year China Aging Development Plan [2]. Perfect community care balances the trends of social services and traditional ethics demand of family care, representing the development direction of China's pension model. Under the severe aging background, most China's communities are faced with the problems of upgrading to or construction for age-friendly communities. However, Community care obviously require a higher quality environment design and facility configuration, needing to improve the design theories or methods, and evaluation index system.

\section{Relative Terms}

"Community" refers to the social community composed of homogeneous population with same value orientation, closely related, friendly, mutually supported, and humane [3]. Wherever, there is no clear definition of "community" concept in China's urban plan and architecture disciplines. Our research group found "community" concept in "community committees" of real life civil administration field in cities across China, whose larger units are equivalent to residential districts, medium ones equivalent to residential quarters, and smaller ones equivalent to residential clusters, overall close to the "residential quarter" concept. Therefore, for convenience research in the field of urban pan and architecture, the "community" term of the subject is defined as residential quarter. According to China's elderly Protection Act, the definition of the elderly is currently defined as 60 years.

At present, the problems of a large number of domestic communities constructing for the elderly have put forward specific demands for a research subject - evaluation index system for age-friendly community, as a significant part of our program Research on Theories \& Methods of New Dwelling 
Environment Construction Based on Home-based Care System. So the research approaches of literature and investigation were identified to build an evaluation index system, trying to dig out major breakthroughs direction from the complex systems engineering of retirement community design.

\section{Research status domestic and abroad}

There are such major social pension models in the United States as assisted living communities, skilled nursing facilities, continuing care retirement communities, and so on according to health status of the elderly. Many government and civil society organizations have raised evaluation criteria for retirement communities. For instance, non-profit organization Association of Retired Persons (AARP) issued livable communities: an evaluation guide, latest version in 2005 [4], covering 8 sub-indexes content as transportation, walkability, safety \& security, shopping, housing, health services, recreation and cultural activities, and the caring community, each with a checklist; Professor Victor Regnier of University of Southern California proposed 100 Critical Considerations for Assisted Living Design, including 10 aspects as neighborhood and site issues, outdoor landscape, important design attributes, stimulating social interaction, extending independence, stimulating the senses, creating affect, planning the dwelling unit, engaging the staff, designing for dementia; the U.S. Environmental Protection Agency has an program Building Healthy Communities for Active Aging Award (BHCAA) and proposed 4 categories of evaluation criteria as exercise, socializing \& work, dwelling space design, transportation, and health services.

Japan has the highest proportion of elderly population over the world, sharing similar cultural traditions with China. Its socialized pension models four types in accordance with the principal part of investment or services, that are government agencies, government-funded organizations, volunteers and their organizations, and enterprises services. Japan's evaluation criteria for retirement communities is mainly focused on aging services, such as the function and service evaluation on nursing homes in 1988 and services evaluation criteria for special nursing home and gerocomia facilities in 1993. Specific standards by the Ministry of Health and Welfare, include 4 types of contents as "input, process, outcome and effect", covering assisted living services, professional services, communicating with relevant agencies, and management services, established a total of 100 criteria with checklists[5]. Access rules were set for facilities, equipments, stuff, services, management of nursing agencies, and there are also accessible design standards such as residential design standards adapting to longevity society in 1995. There are many related evaluation indexes in Japan, but no quantitative criteria for community and architecture design-related content.

The World Health Organization also made related evaluation indexes, such as Checklist of Essential Features of Age-friendly Cities, whose latest edition published in 2007[6], including outdoor spaces and buildings, transportation, housing, social participation, respect and social inclusion, civic participation and employment, communication and information, community and health services, a total of eight areas.

Currently there are less relevant domestic research literature, that only one evaluation index can be found is "China Joint Assessment system for Green Retirement Settlements" by Nie Meisheng, but no survey data or other scientific basis supported. There are several design standards such as "Code for urban residential areas planning and design", "Design code for elderly buildings", "Design standards for elderly residential buildings", "Construction standards for day care center for the aged", "Construction standards for nursing home for the aged", etc, but far from forming a complete evaluation system. Therefore, the subject is not only strongly realistic and targeted, but also has higher academic value. 
Table 1 The framework of the evaluation index for age-friendly community

\begin{tabular}{|c|c|c|c|}
\hline Indicator & Score & Sub-indicator & Score \\
\hline \multirow{9}{*}{$\begin{array}{l}\text { Facilities around } \\
\text { the community }\end{array}$} & \multirow{9}{*}{121.1} & location & 7.5 \\
\hline & & Environment conditions & 12 \\
\hline & & Transportation facilities & 3.5 \\
\hline & & Business facilities of the residential district & 9.5 \\
\hline & & Education facilities & 2 \\
\hline & & Property and civil facilities & 2.5 \\
\hline & & elderly facilities & 63.3 \\
\hline & & Health facilities & 8 \\
\hline & & Culture, sports \& entertainment facilities & 12.8 \\
\hline \multirow{8}{*}{$\begin{array}{l}\text { Facilities in the } \\
\text { community }\end{array}$} & \multirow{8}{*}{68.5} & Business facilities of the residential quarter & 16.1 \\
\hline & & Communication facilities & 3 \\
\hline & & Transportation facilities & 3.5 \\
\hline & & Education facilities & 1.5 \\
\hline & & Property and civil facilities & 5.2 \\
\hline & & elderly facilities & 22.6 \\
\hline & & Health facilities & 7 \\
\hline & & Recreation \& communication space & 9.6 \\
\hline \multirow{5}{*}{$\begin{array}{l}\text { Environment in the } \\
\text { community }\end{array}$} & \multirow{5}{*}{93.7} & greening environment & 9 \\
\hline & & pollution prevention & 12 \\
\hline & & fire safety & 33 \\
\hline & & Traffic Safety & 21.7 \\
\hline & & Security & 18 \\
\hline \multirow{7}{*}{ Dwelling space } & \multirow{7}{*}{94.6} & Amount of accessible \& elderly dwelling units & 1.5 \\
\hline & & interior space of the elderly residence & 51.4 \\
\hline & & public space accessible design of the residential buildings & 19.3 \\
\hline & & Home Injury prevention & 4.5 \\
\hline & & interior architectural physics environment & 10.1 \\
\hline & & Green building materials & 3.8 \\
\hline & & home security monitoring devices & 4 \\
\hline \multirow{8}{*}{$\begin{array}{l}\text { Services, } \\
\text { management \& } \\
\text { operation }\end{array}$} & \multirow{8}{*}{96.1} & service \& Management of the elderly care institutions & 20.3 \\
\hline & & Information Management for the elderly & 5.5 \\
\hline & & Service of Civil Affairs \& neighborhood committee & 4 \\
\hline & & Community property owner committee & 1.5 \\
\hline & & Property Management \& Service & 19.8 \\
\hline & & Management \& Service of community health institutions & 12 \\
\hline & & Food \&Environment Safety of Community Kitchen & 15.5 \\
\hline & & Safe quality & 17.5 \\
\hline
\end{tabular}

\section{Investigation overview}

Through extensive investigations on real life and demands of the elderly in communities of Tianjin City, the specific requirements of the retirement community evaluation index can be conducted, base on China's conditions and social development.

The investigation collected 30 typical communities from the 11 districts in Tianjin City, each with more than 15 questionnaires about real retirement life status and demands, as well as objective investigation on facilities distribution in and around the community. Thus a number of problems such as deficiencies were found in the first phase of the index drafting process, therefore lots of evaluation indicators were also mended. 


\section{The framework of the evaluation index}

By analyzing domestic and international evaluation laws, standards, literature about age-friendly communities, assessment indexes for retirement are sorted in accordance with the space (agency) or performance, especially that the former is more common. According to space commonly applied in domestic planning of residential areas, five indicators and their sub-items were identified for retirement communities as followed Table 1 .

The contents of the evaluation index system should cover all areas of planning, design, management and services, and obviously the weight of each indicator, including subsidiary and tertiary indicator should not be totally equal. The first level indicator weights were mainly determined by quantitative statistical correlation between subjective evaluation item levels, also mended by experts. The subsidiary indicators was determined mainly by AHP analysis and expert assessment, supplemented by subjective investigation data statistics, whereas the tertiary indicators (not listed in this article due to limited space) are mainly by investigation data statistics and expert evaluation. Thus the score of each indicator was achieved. The evaluation index system need to be improved and verified in the future practice and research.

\section{Conclusions}

Planning, design, construction and development of age-friendly community is a systematic project. The establishment of evaluation index for it can provide quantitative, specific, and operational guidelines and norms, conducive to assessment, monitoring and decision for building management department, helpful to attract the elderly and the whole society to participate in aging environment construction, and will ultimately make contribution to build a human settlement environment for the elderly with a treasure sense of belonging, security, worthiness and happiness.

\section{Acknowledgements}

This work was financially supported by Application Foundation and Frontier Technology Research Program of Tianjin (15JCYBJC22200).

\section{References}

[1] National Bureau of Statistics of People's Republic of China. Communiqué of the Sixth national census data in 2010(2011)

[2] China General Office of the State Council. the "12th Five Year" Plan for Aging undertaking Development (2011)

[3] Toennies, translated by Lin Rongyuan. Community and Society (in Chinese). Beijing: The Commercial Press(1999)

[4] Arizona State University, Herberger Center for Design Excellence. Livable Communities: An Evaluation Guide[R]. AARP Public Policy Institute(2005)

[5] Wang Lifang. The Japanese Evaluation System of Elderly Caring Service and Its Implications for China. Journal of Zhaoqing University, Vol.31 (2010), p. 45-50

[6] WHO. Checklist of Essential Features of Age-friendly Cities. http://www.who.int/kobe_centre/publications/age_friendly_cities_guide/en/ 